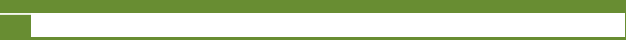

SECCIÓN: Teorías geográficas, geografía de la cultura y la vida cotidiana

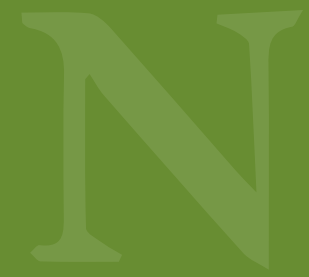

\author{
cultura y la vida cotidian
}
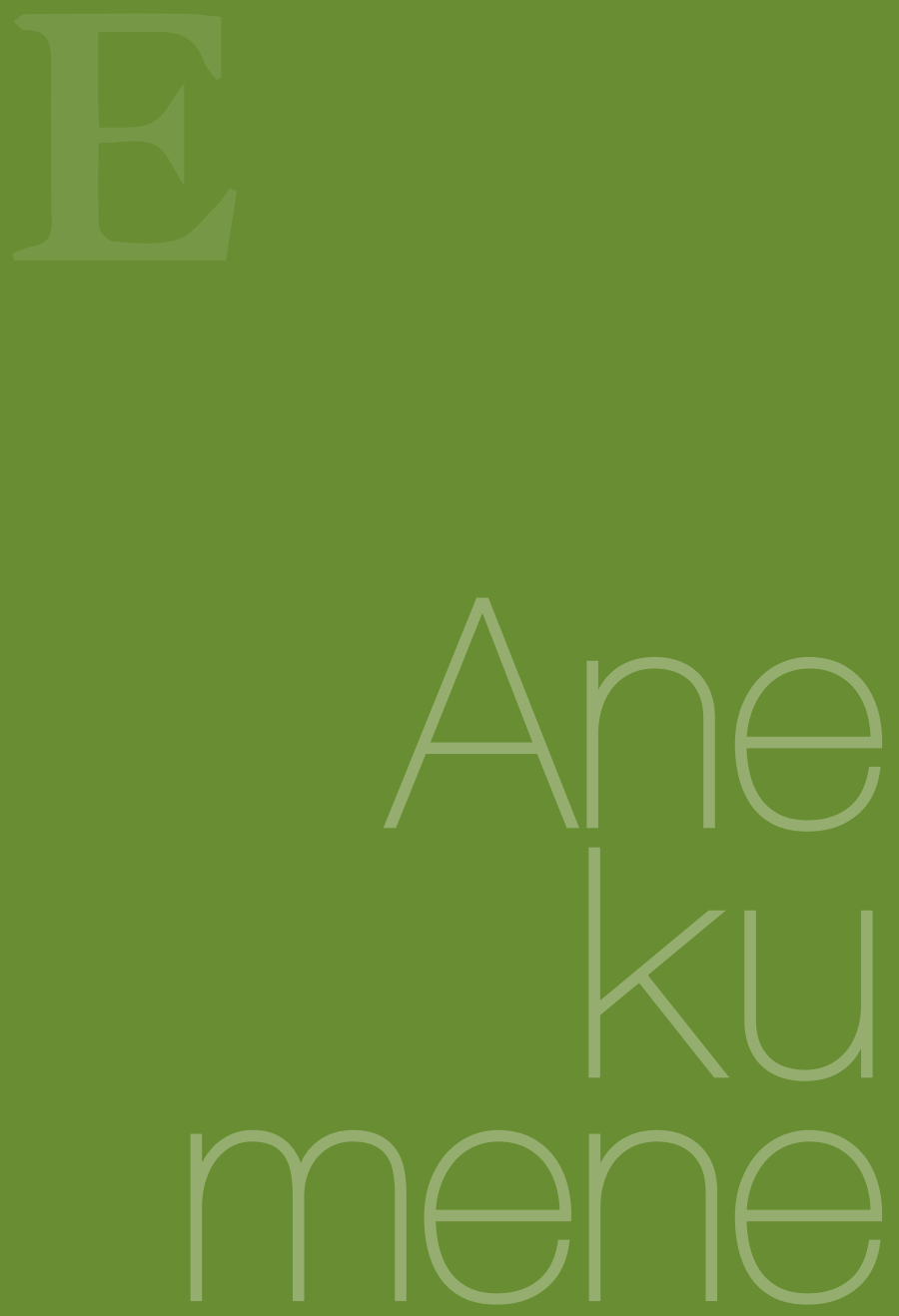


\section{El metro imaginado y la plaza del maestro}

\section{The Imaginary Subway and the Theacher's Square O metrô imaginado e a praça do maestro}

Luis Felipe Castellanos Sepúlveda ${ }^{1}$

\section{Resumen}

El presente texto fue presentado durante un conversatorio sobre problemas urbanos contemporáneos. Es un relato en medio de detalles del pasado, el presente y el futuro de la experiencia urbana de los bogotanos sobre el proyecto, siempre inconcluso, de la construcción de un sistema de metro para la ciudad. Esta experiencia conlleva reflexionar sobre la calidad del espacio público y el valor de la configuración de imaginarios en la planeación de la ciudad.

\section{Palabras clave}

Bogotá, metro, paisaje urbano, imaginarios urbanos, espacio público.

1 Profesor, Universidad Pedagógica Nacional. 


\section{Palavras chave \\ Bogotá, metrô, paisagem urbano, imaginário urbanos, espaço público.}

\section{Keywords}

Bogotá,

subway system, cityscape, urban imaginary, public space.

\section{Resumo}

Este trabalho foi apresentado em uma conferência sobre os problemas urbanos contemporáneos. Lê-se como uma história, detalhando o passado, presente e futuro da experiência urbana dos cidadãos, projeto sempre inacabada na construção de um sistema de metrô para a Bogotá: esta experiência permite-nos a pensar sobre a qualidade do espaço público eo valor intrínseco do imaginário no planejamento da cidade.

\section{Abstract}

This paper was presented at a conference on contemporary urban problems. It is a story of the past, present and future details of the urban experience of Bogota people about the unfinished project of a subway system. This experience brings a reflection about the quality of public space and the value of imaginary settings in city planning. 


\section{Transporte y movilidad en Bogotá}

Paseaba en su bicicleta el candidato a la alcaldía, doctor Enrique Peñalosa, acompañado por sus seguidores y por un periodista de un noticiero nacional que le preguntaba sobre sus propuestas de campaña. De repente, un peatón le grita desde la otra acera: "¡Yo quiero metro! ¡Yo quiero metro!". El lúcido ciclista se detiene y le contesta, a voz en cuello: “¿Claro que sí, lo vamos a construir!”. El periodista, pertinaz como siempre, le pregunta al peatón: "Quiere el metro por encima o por debajo?, “iPor debajo, claro, por debajo!” fue la respuesta.

Al eterno candidato ${ }^{2}$ le cambió la expresión del rostro; no coordinó en adelante ni un solo pedalazo y se empeñó en defender su idea: un metro completamente subterráneo generaría sobrecostos a la ciudad del orden de 65 a 100 millones de dólares por kilómetro; él propone un metro elevado, barato, que no supere el estimado de 200 millones de dólares por kilómetro, con las características del suelo de la Sabana de Bogotá, sería lo más conveniente. En suma, al doctor Peñalosa le gustaría un metro por encima, como se lo hicieron a Medellín.

Hace unos 18 años, cuando le ganó las elecciones locales a Carlos Moreno de Caro y a Antonio Galán Sarmiento, tremendos competidores por la alcaldía, esa campaña no versaba tanto sobre millones de dólares adicionales, ni mucho menos, sobre los suelos de la Sabana; a la postre, construiría la primera fase del sistema Transmilenio con el relleno fluido que le vendieron Cemex y Asocreto, y que terminó en un reguero de losas quebradas por la lluvia y el peso de sus votantes subidos en buses importados de Brasil. Eso le generó a la ciudad un gasto de 300.000 millones de pesos por reparaciones que el Distrito pagó porque la investigación contra Cemex y Asocreto preescribió hace apenas unas semanas, por decisión del Tribunal Administrativo de Bogotá.

El anuncio de asumir la responsabilidad política de la tronera de la Avenida Caracas y la Autopista Norte le quedó a Peñalosa en planes, porque ya tiene en su haber desde entonces tres candidaturas a la Alcaldía Mayor y unas cuantas más a la presidencia, y ahora, cuando le gustaría un metro elevado, la propuesta de campaña se va sumando a la seguidilla de obstáculos para este proyecto en Bogotá.

Un metro elevado no se lo deseo a Bogotá. Bogotá tiene cerros en todas las direcciones, los bogotanos tenemos el horizonte truncado. Una barrera más en el paisaje de la ciudad plantea problemas de orden urbanístico muy importantes: por ejemplo, no les dejaría ver a mis estudiantes desde sus ventanas esos espléndidos amaneceres (a veces, a las 5:30 a.m. o a las 6:00 a. $\mathrm{m}$.) o esos atardeceres en tonos violáceos y rojizos que me aferran más a esta ciudad donde la noche tiene las mismas 12 horas de oportunidad que el día.

2 Luego fue elegido alcalde mayor de Bogotá el 25 de octubre de 2015, para iniciar un periodo de cuatro años de administración desde el $1^{\circ}$ de enero de 2016.
$\mathrm{Y}$, ¿para qué le sirve el paisaje a una ciudad? Habrá que preguntarles a los habitantes de Barcelona, de Estambul, de París, de Nueva York, de Kuala Lumpur, de Roma o de Buenos Aires: algunas de las ciudades más visitadas actualmente por el turismo. El paisaje hoy por hoy se convierte en un valor constitutivo de la identidad de las ciudades y de sus ciudadanos; es decir, es un derecho que permite reconocer el origen, la forma y la función de lo urbano.

Para Bogotá no quiero una serpiente endemoniada, ruidosa y llena de gente circulando afanosa por entre barrios, parques y plazas; eso se lo dejo a Medellín, que sí tiene metro, un canal gris que corta quirúrgicamente la ciudad, pero que, por fortuna, no opaca la montaña. Medellín es montaña, y ni este, ni el tranvía, ni el Metro Cable ni el Metro Plus les quitan el goce de la montaña a millones de personas en una ciudad que apenas si he visitado una vez, y de la cual no puedo hablar mucho.

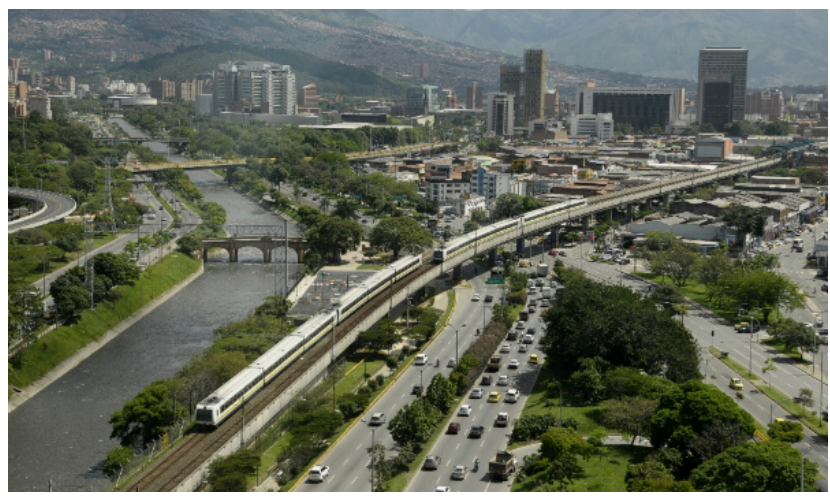

Figura 1. Metro de Medellín

Fuente: Jhon Alexander Chica Yara. Recuperada de: http://www. elmundo.com/portal/noticias/movilidad/metro de medellin sobresale en alamys.php

Ese fue el primer metro en el que yo monté; “iEsta gente sí lo logró!”, pensé. Con deuda y todo, con filas y todo, con caos y todo, con hinchas verdes y rojos colapsándolo y todo, ahí se mueve el tren blanco entre la montaña. Recuerdo en la televisión al presidente Ernesto Samper en 1995, pulsando un botón para dar inicio a la operación, como pensando “i¿Yo en qué problema me metí?!”. Mucho tiempo después, supe que Medellín tiene 80 años para pagar esa plata; más o menos, unos 2.200 millones de dólares. Al parecer, les fue bien; a nosotros nos va a costar entre 5 y 7 mil millones de dólares, de los cuales el 70\% será financiado por cupo de endeudamiento con la Nación, y el 30\% restante, con las reservas del Distrito, si se cumple, si se hace ${ }^{3}$.

3 En los primeros días de la administración del alcalde Enrique Peñalosa (enero de 2016) se ha anunciado la modificación del trazado inicial que se había propuesto con los estudios técnicos más recientes. Una eventual línea de metro recorrería la ciudad desde el borde suroccidente de la ciudad hasta el Centro Internacional, para hacer conexión con el sistema Transmilenio. El trazado inicial contemplaba un desplazamiento hasta el norte de la ciudad, con lo cual se pretendía descongestionar el borde oriental de circulación, que, históricamente, ha sido el más congestionado de la ciudad. 
El metro de Medellín tiene 20 años; yo soy más viejo. El metro de Londres (el underground, con 11 líneas en operación, y visitado por los fans de Harry Potter en la estación King's Cross, para ver si cruzan a la dimensión mágica, lo que no sería raro después de tanto tiempo de funcionamiento) tiene 157 años. El metro de Nueva York tiene 111 años y el reloj de su gran estación central sigue andando; como el reloj de Taylor, "el tiempo es dinero", repite.

El metro de Ciudad de México cumplió el pasado 4 de septiembre 47 años, circulando en una ciudad que se hunde entre 5 y $10 \mathrm{~cm}$ al año, y que, por suerte, - o por mano de la Virgen de Guadalupe o de Quetzalcóatl-, no se hunde más, aun soportando a 20 millones de personas que caminan todos los días en su zona metropolitana. Un metro joven en una ciudad vieja es un hervidero de relaciones, cruces, miradas y choques; imágenes que no he visto, roces que no he sentido y olores que no he olido.

El olor que sí recuerdo, y del que quedé prendado en pocos días, es el olor a jabón de manos, suave, higiénico, que va in crescendo en cada vagón y cada corredor del metro de Buenos Aires. Pensé que era impresión mía o una casualidad, pero cada vez que subía al Subte -como le llaman allí cariñosamente al Metro- me llegaba el bienestar de ese olor particular que me hacía sentir seguro y menos desorientado en esa ciudad ajena. Asumí luego que era el humor del Subte, la suma de los olores de alrededor de un millón de pasajeros que lo abordan a diario. Y me subía -o, más bien, me bajaba - en la estación Palermo, línea D, que discurre por el norte de la ciudad, y llegaba en 15 minutos al centro de la ciudad, en la Estación Catedral, o iba a la intersección Carlos Pellegrini / 9 de Mayo, para llegar a esa hermosa estación de trenes de Constitución, que daba entrada al sur del Gran Buenos Aires.

En medio de tantísimos nombres, tan sonoros, tan afirmativos, como Carlos Gardel, Pueyrredón, Plaza de Mayo, Plaza Italia, Tribunales, Once, Corrientes o Facultad de Medicina, me preguntaba: ¿cuáles serían los nombres de las estaciones del metro de Bogotá? ¿Qué capricho político o cultural sería el determinante para nombrar cada estación? ¿Cuántos nombres memorizaría desde mi punto de partida hasta mi destino habitual?

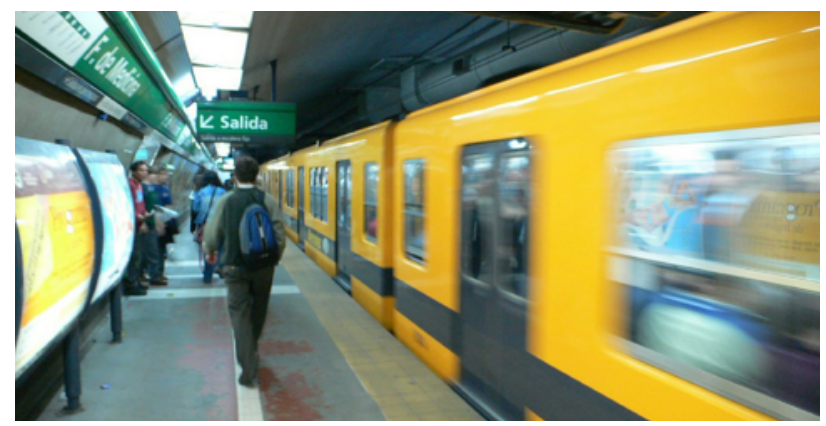

Figura 2. El Subte

Fuente: foto recuperada en: http://www.enelsubte.com/
El metro de Buenos Aires va para 102 años, y veía a mi alrededor su funcionalidad programada, un exceso de orden, un conformismo en cada acción y cada objeto; demasiado predecible para mi costumbre. Entonces deseé llegar a Bogotá y untarme de caos, de estrés, de mugre y de esos olores muy nuestros que, al fin y al cabo, son lo que tenemos. Deberían echarles un vistazo a los mapas de estaciones de los metros más importantes del mundo, a la forma, a las trayectorias, a la dirección, a los puntos, a la alternancia de las líneas y, por supuesto, a los nombres de las estaciones; es un derroche de variables cartográficas que identifican a cada ciudad, que expresan el tejido urbano y, sobre todo, espacializa la cultura urbana de cada sociedad - sea esta oriental u occidental, desarrollada o subdesarrollada-frente a la necesidad de movilidad.

Los metros son el sistema circulatorio de las ciudades contemporáneas, pero digo los metros, no los transmilenios ${ }^{4}$. Esos no hacen circular nada: son contaminantes y patrocinadores del imperio del automóvil y del combustible fósil (grandes marcas como Volvo, Scania y Mercedes Benz). Estaba equivocado Peñalosa con eso de la sangre que circula por las venas; más bien, nos trajo una enfermedad coronaria, la várice más terrible, y la vendió a otras ciudades como la solución, la cura a los males de circulación. Así se la pasa este vendedor de ilusiones, emulando a sus coterráneos de la costa este de los Estados Unidos.

Pero, mejor, quiero hablarles desde los imaginarios. El metro de Bogotá tiene casi la edad que tiene mi madre, o un poco más. Fue inaugurado en 1942, durante el segundo periodo presidencial de Alfonso López Pumarejo y bajo la alcaldía del ingeniero civil Carlos Sanz de Santamaría, notable constructor de cosas bajo la tierra (acueductos y alcantarillados); no obstante, las obras no se concretaron ni los estudios tuvieron repercusión alguna en la ciudad, y en reemplazo, el metro se inauguró en la imagen de los bogotanos con el nombre de algo más simple y atractivo: el trolebús operado por la liquidada Empresa Distrital de Transportes Urbanos (EDTU). Hacia 1948, los trolly llevaban a los estudiantes desde el centro hasta la Ciudad Universitaria y de vuelta, y hacían la ruta hasta La Hortúa pasando por Los Mártires. Nuestro metro imaginado fue, en principio, una seguidilla de adquisiciones de buses usados de ciudades como Kansas, Maryland y Baltimore, y luego, una flota de buses de fabricación soviética que llenó de vistosos anuncios publicitarios la Bogotá de los años setenta y ochenta del siglo XX; hasta finales de los ochenta, apestaban a orines $y$ frecuentemente se despegaban de la red aérea de cables que se les daban energía e impulso, según me contó mi papá.

Durante el gobierno de mi general Rojas Pinilla, el metro imaginado circuló en forma de maquetas y mapas por su despacho; firmas canadienses

\footnotetext{
4 Los sistemas Buses de Transporte Rápido (BRT) proliferaron recientemente como solución a los problemas de movilidad e integración de sistemas de transporte público masivo en ciudades intermedias del mundo; el sistema BRT de Bogotá tiene una de las demandas más alta por día en Latinoamérica (un estimado de 1’450.000 usuarios).
} 
y japonesas se interesaron en proponer una solución para Bogotá. “Qué tal un monorriel, general?... ¿Qué tal un metro ligero, Su Excelencia?”. Y él lo pensaba y lo pensaba. Lo pensó tanto que llegó el Frente Nacional e hizo caer esta idea, y tantas otras, bajo los escritorios de la burocracia bipartidista. ¿Quién iba a imaginar que el nieto de mi general, hijo de $L a$ Capitana, unas décadas más tarde, iba a darle forma -o, por lo menos, presencia escénica- a este metro imaginado? Unos videos muy difundidos que lo mostraban flamante, reluciente, amarillo y blanco, llegando a las estaciones, titilando orgulloso su nombre, veloz, límpido cual carrusel recién puesto en el parque. De tal palo tal astilla, mi general Rojas Pinilla: ya casi que sus bisnietos se pueden dar una vuelta en ese carrusel.

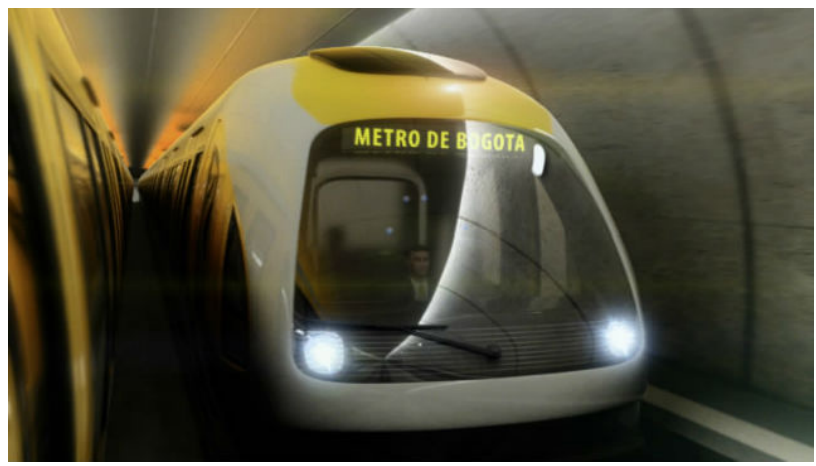

Figura 3. Proyección del metro de Bogotá Fuente: foto recuperada de http://www.bogota.gov.co/sites/default/ files/metro\%20bogota.jpg

Tampoco Virgilio Barco, notable urbanista, les halló la entrada a las estaciones del metro: se quedó haciendo su Ciudad Salitre con mucho ahínco, y durante su mandato presidencial no hizo lo que su colega presidente Belisario Betancourt por la capital de su natal Antioquia, al darles vía libre a los estudios de factibilidad y posterior licitación de las obras del metro de Medellín.

A nuestro metro imaginado le apareció su antítesis en la forma del sistema Transmilenio, hacia el inicio del siglo XXI; no fue su reemplazo ni una alternativa: más bien, fue su negación. Una negación que ha cambiado atropelladamente los significados y los sentidos que las personas tienen sobre un aspecto básico en su relación con la ciudad: el recorrido que hacen diariamente de su lugar de residencia a su lugar de trabajo o estudio.

¿Cómo puede un desplazamiento de 40 minutos (en 2005) convertirse en un desplazamiento de casi 120 minutos en la actualidad? Bueno, a mí me pasó y me pasa, y podría quejarme tanto como quisiera de esta amarga certeza; no obstante, si en algo puede ayudarnos la geografía para comprender estas situaciones es en el sentido de vincular las experiencias de los sujetos habitantes de la ciudad con el sistema de objetos que ha construido la sociedad para su despliegue espacial.
Las acciones se materializan en el espacio en forma de técnicas, en forma de transmilenios chocándose unos contra otros, en forma de puertas de estaciones inservibles o de una malla vial deteriorada, es el despliegue de un acumulado de fracasos urbanos que nos enfrenta con el caos y la mala calidad de vida actual. No defendimos en su momento la posibilidad de que Bogotá tuviera un sistema de transporte acorde con sus expectativas, con la cantidad, la diversidad y el carácter de sus ciudadanos; desistimos de nuestro metro imaginado al tiempo que invertimos recursos y esfuerzos en enriquecer a muy pocos y en deteriorar nuestros vínculos cercanos con otras personas en los espacios públicos, elegimos un sistema masivo de transporte que, a la postre, exaltó lo peor de nosotros: la violencia.

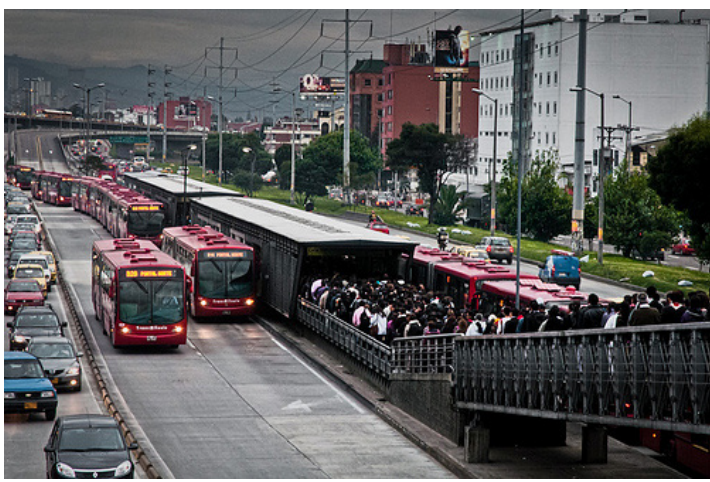

Figura 4. Transmilenio de Bogotá

Fuente: recuperada de: http://www.institutodeestudiosurbanos.info/ cache/com_zoo/images/Transmilenio_638ed953a06aa3835e662fc25d7167aa.jpg

No quiero decir con esto que el metro como técnica y como experiencia urbana sea la solución a nuestros problemas urbanos más acuciantes: solo pienso que hemos desistido de la gestión de nuestra experiencia urbana y hemos enfatizado en la gestión del espacio urbano, como si se tratara de un escenario estático de nuestras acciones.

Cuando la pala de las retroexcavadoras cayó sobre las casas del histórico barrio Santa Inés, cuando las Galerías Nariño fueron arrasadas para hacer una plazoleta, cuando se puso un parque al lado de un cementerio, cuando se construyeron extensas ciudadelas de vivienda hacia el borde occidental colindantes con el río Bogotá, y en otros tantos momentos coyunturales, se actuó bajo el estándar de la planeación de la ciudad, sin tener en cuenta la planeación de la vida urbana ${ }^{5}$.

5 Estas acciones de renovación urbana y recuperación del espacio público en la ciudad fueron concebidas durante el primer gobierno de Enrique Peñalosa y los gobiernos de Antanas Mockus, a finales de la década de 1990 y principios de la de 2000. Un periodo precedente de deterioro del espacio público y de incremento de la violencia urbana justificó estas medidas ante los ciudadanos y la expectativa de un futuro promisorio para una urbe en constante crecimiento. 
Cuando la tierra arrasada se impone como política de renovación de la ciudad, ningún megaproyecto podrá borrar las huellas que deja el tejido social y la memoria en el espacio. Ciudades del miedo, del caos, de la muerte, de la crisis económica, del deterioro, del crimen y de la desigualdad persistirán en medio de parques, alamedas, centros comerciales y grandes autopistas.

En una columna de 1993, sobre la posibilidad de construcción del metro en Bogotá, Armando Silva define sus propias estaciones temáticas para abordar el metro imaginado: la estación del desespero (los empleados yendo hacia sus trabajos y regresando a sus casas); la estación del compromiso, que en ese momento se vislumbraba como una actitud de brazos cruzados de la ciudadanía frente al metro; las estaciones del rebusque, la violencia y la locura, que plantean las prácticas cotidianas del bogotano que impregnarían cada espacio del eventual metro, y una estación de la imaginación, donde el autor plantea su visión acerca de los imaginarios urbanos:

Los nombres que se dan a las estaciones funcionan para los ciudadanos como una gran metáfora de lo que una ciudad quiere destacar para el recuerdo. Y dependiendo del acierto de sus bautismos, una ciudad logra hacer de este mapa subterráneo no sólo los viajes reales, sino el itinerario fabuloso de lo que significa ser ciudadanos de una ciudad (Silva, 1993, p. 75).

De este metro imaginado tengo mi propia versión. Sin embargo, aclaro, el imaginario no se construye solo en un plano individual: más bien, es un imaginario con los otros; en este caso, en la vecindad y la simultaneidad con los otros en la vida urbana. Por tanto, todo imaginario es territorial y espacial, tiene nombre propio, es localizable y tiene una situación.

A mí me parece muy conveniente este reciente metro imaginado. Sale del Portal de Las Américas, cerquita de mi barrio, y va buscando el Oriente, pasando por una bella estación central en la Avenida Caracas con Calle 26.

Me salto sus posibles paradas para llegar a mi destino, a mi otro barrio: Chapinero. Tendrá que llegar el metro por la carrera 13 hasta la calle 63. Allí, mi primera propuesta para el nombre de esa estación: se debe llamar Lourdes, a secas, como esa Virgen traída de Francia que en más de 100 años de estancia en esta ciudad se ha vuelto una señora muy tolerante y muy alcahueta. Lourdes, estación de la Virgen diversa que acoge en su seno a los parias de esta ciudad hipócrita, a los invisibles.

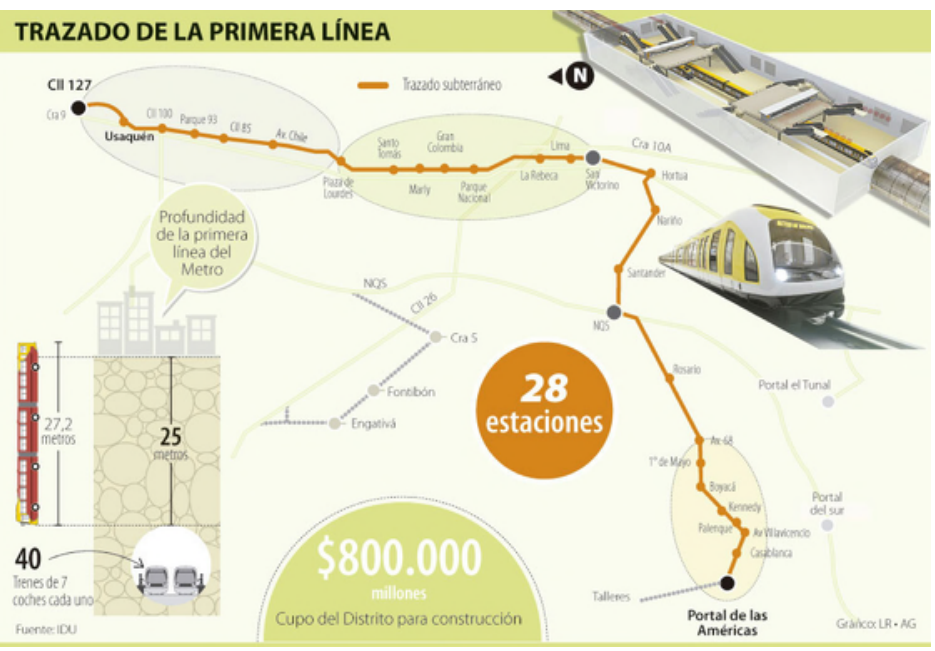

Figura 5. Trazado de la primera línea del metro de Bogotá (proyección) Fuente: recuperada de: http://www.canalcapital.gov.co/blogs/wp-content/uploads/2014/10/metro-la-republica.jpg

Ahí me quedo: en Chapinero, en Lourdes, a recorrer las calles que conocí por medio de las descripciones de Daniel Ortega Ricaurte, la curiosidad arquitectónica de Carlos Martínez y las múltiples ciudades de ensueño y borracheras de Chaparro Madiedo, Antonio Caballero Calderón, Héctor Abad Faciolince y Andrés Ospina. Las calles que sigo conociendo con una insistencia casi angustiosa; sobre todo, en la noche, porque es cuando Chapinero sale del clóset.

Más al norte se detiene el metro y llega a la calle 72 con carrera 11. Aquí sí, si se me permite, y ante la gama de posibilidades para nombrar a esa estación, les propongo cortar por lo sano. Los vecinos son famosos por antigüedad y por el ruido que generan, y nuestra Universidad cumple bien con estas dos condiciones.

Así pues, los invito a la estación Universidad Pedagógica Nacional del metro de Bogotá ${ }^{y}$ y su plaza del maestro. Porque cada estación grande debe tener su plaza, como en Buenos Aires. A cada gran verticalidad hay que asignarle una horizontalidad: de lo contrario, la ciudad se torna hostil.

6 En el trazado propuesto, la estación figura con el nombre "Avenida Chile", que atendería al pasado de este sector de la ciudad, construido y conservado por la élite política y económica de hasta bien entrado el siglo XX, como un lugar de retiro y descanso alejado del centro tradicional, caótico y atiborrado; no obstante, la Misión Pedagógica Alemana, liderada por Francisca Radke, se estableció con su Escuela Normal para Señoritas, hacia la década de 1930, lo cual dio paso a una tradición importante de formación de maestras y maestros luego, con la creación de la Universidad Pedagógica Nacional, en 1955. 
Salgo del subterráneo y me encuentro con la universidad que sueño, no sin antes atravesar esa plaza llena de rostros y miradas familiares. Esa plaza ha de tener en cuantas placas sea posible como un hall de la fama a Francisca Radke y a Darío Betancourt juntos, reconciliados; también, merecidas menciones a mis profesores Jorge Mora Forero, Danilo Carantón y Amanda Rodríguez de Moreno ${ }^{7}$. Tendrá un cafecito muy sencillo, fiel reproducción de la caseta que había hace unos años, donde atenderán, también como ayer, esas hermosas señoras de sonrisa amable vestidas de blanco y con sus delantales azules.

En el centro de esa plaza, lo más importante: un monumento en honor al maestro. Una mujer y un hombre de bronce, de actitud altiva mirando al oriente, cargando sendos morrales rebosantes de libros y papelería. Yen su zócalo, una inscripción dorada que diga: "Los profes: Ministra, yo no me gano 2 millones de pesos"8.

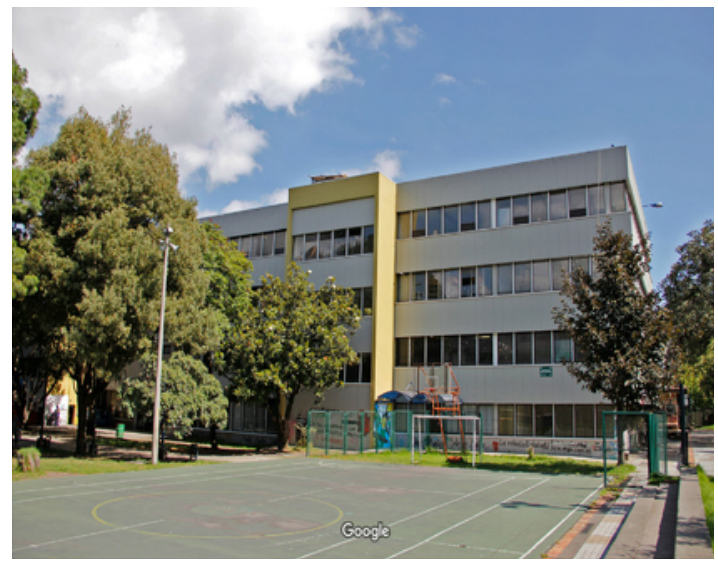

Figura 6. Universidad Pedagógica Nacional

Fuente: recuperada de: Google Maps Street View https://goo.gl/maps/ vhf68yv39DC2

Y la universidad, bueno, sería muchas cosas: una síntesis del tamaño de mi afecto por ella, pero, para resumir, quisiera una universidad donde puedan venir los niños a ver sus clases. Basta de practicantes universitarios revoloteando de colegio en colegio: que los niños y sus padres vengan sin miedo a conocer la universidad, que aprendan geografía e historia, que hagan experimentos en los laboratorios de biología y química, y reco-

\footnotetext{
7 Profesores todos del Departamento de Ciencias Sociales de la Universidad Pedagógica Nacional que han dejado una huella en el campo de la enseñanza de la geografía y la historia; en la actualidad, están retirados de sus actividades docentes y han recibido reconocimientos por sus trayectorias en varias instancias académicas.

8 Durante mayo y junio de 2015, se realizó una huelga del sindicato de maestros de Colombia (Fecode), para exigir un aumento considerable en el salario de los maestros de escuelas públicas. La ministra de educación de ese entonces, Gina Parody, aseguró en varias ocasiones que buena parte de los maestros devengan salarios de alrededor de 2 millones de pesos, lo cual mereció miles de respuestas indignadas, por el desconocimiento de las condiciones salariales del gremio.
}

rridos en los alrededores; que jueguen con los estudiantes y disfruten de la música y los murales en cada rincón, de una clase de natación en la piscina y de la lectura en voz alta de cuentos y poesía en la biblioteca.

Yo no acabaría la calle del pecado ${ }^{9}$, pecar es necesario para no enloquecer en medio de tanta formalidad. No obstante, es bueno anunciar a la comunidad universitaria con un aviso así: "¡Cuidado, no peque!: niños aprendiendo en la calle".

A todas estas, en estos días mi experiencia y yo cumplimos diez años en esta universidad, y así como el venado de San Francisco de Asís desapareció, el caballito de Granahorrar ya no galopa y las vacas del Banco Ganadero ya no mugen ${ }^{10}$, la ciudad cambia en poco tiempo, y si el metro de Bogotá, el que vale 13 billones de pesos, pasara por estos predios, por abajo, como debe ser, esta universidad debería cambiar, no irse del barrio, como dicen algunos.

A la sede de Valmaría ${ }^{11}$ no debemos trasladarnos. Valmaría no es nuestra, está lejos, es un humedal para aves migratorias, no para una universidad de más de 8.000 personas. Es un lugar sin memoria, sin significados que la afirmen en nuestra experiencia. Valmaría es un mal sueño. Hay que levantar todo lo que hay allá y traerlo acá, a donde pertenece.

\section{Referencias}

Silva Silva, A. (1993). La fábula del metro. Recuperado el 7 de septiembre de 2015 de: http://www.eltiempo.com/archivo/documento/ MAM-256300
9 Dentro del ámbito universitario "la calle del pecado" hace referencia a un espacio determinado dentro de la Universidad que está relacionado con el consumo y venta de sustancias psicoactivas por parte de los estudiantes; recientemente, se han realizado acciones afirmativas para cambiar el imaginario acerca de este lugar y para contrarrestar estas actividades que afectan negativamente la vida universitaria.

10 Todas estas figuras, monumentos o estatuas hasta hace unos lustros permanecían como símbolos de bancos y órdenes religiosas cercanas a la Universidad Pedagógica Nacional, pero hoy han sido retirados o reemplazadas por otros.

11 Valmaría es un proyecto de renovación y reinstalación del campus universitario en predios ubicados en el norte de la ciudad, un proyecto que requiere una inversión importante, del orden de los 600.000 mil millones de pesos, si se conservara el diseño arquitectónico inicial, elaborado por el notable Rogelio Salmona poco antes de morir. El dilema radica en la insuficiencia de los recursos para ejecutar este proyecto, lo que se suma a la precaria situación en el financiamiento de las universidades públicas en Colombia. 